\title{
Desnutrição protéica no início da vida prejudica memória social em ratos adultos
}

\author{
Early protein malnutrition impairs social \\ memory in adult rats
}

Viviane Consiglio da SILVA ${ }^{1}$

Sebastião de Sousa ALMEIDA ${ }^{1}$

\section{RE S U M O}

\section{Objetivo}

Avaliar se a desnutrição protéica imposta no início da vida produz prejuízos em um procedimento experimental de memória social em ratos (Rattus norvegicus).

\section{Métodos}

Os animais receberam dietas isocalóricas contendo $6 \%$ ou $16 \%$ de proteína do nascimento aos 21 dias, e dieta comercial a partir de 22 dias de idade. O teste de memória social consistiu em, após duas sessões de habituação (7 minutos/sessão), introduzir um animal adulto (100-114 dias de idade) e um outro jovem (30-44 dias de idade) em uma arena de acrílico $(90 \mathrm{~cm} \times 90 \mathrm{~cm} \times 45 \mathrm{~cm})$ em duas sessões separadas por intervalos de 30 (experimento 1) ou 15 minutos (experimento 2). O contato social foi definido como investigação (ato de cheirar/inspecionar a região anogenital). A diferença no tempo de contato entre a primeira e a segunda exposição é considerada um índice de memória social.

\section{Resultados}

Nenhuma diferença devida à dieta foi observada no experimento 1 . No experimento 2 houve redução no tempo de contato social dos animais-controle da primeira para a segunda exposição $(p<0,05)$ e não houve alteração nos animais desnutridos.

\section{Conclusão}

Esses resultados sugerem que a desnutrição protéica precoce prejudica a memória social de ratos adultos.

Termos de índexação: desnutrição protéica; comportamento social; ratos.

\footnotetext{
1 Laboratório de Nutrição e Comportamento, Faculdade de Filosofia, Ciências e Letras de Ribeirão Preto, Universidade de São Paulo. Av dos Bandeirantes, 3900, 14040-901, Ribeirão Preto, SP, Brasil. Correspondência para/Correspondence to: S.S. ALMEIDA.

Trabalho financiado pela FAPESP (02/05674-5) e CNPq (470415/03-7).
} 
196 | V.C. SILVA \& S.S. ALMEIDA

\section{A B S T R A C T}

\section{Objective}

The objective of the present study was to investigate the effects of early protein malnutrition on the social memory of adult rats (Rattus norvegicus) using an experimental procedure.

\section{Methods}

The animals received isocaloric diets containing $6 \%$ or $16 \%$ of protein during the lactation phase $(0-21$ days of age) and a commercial lab chow as from 22 days of age. The social memory test consisted of, after 2 daily habituation sessions (7minutes/session), to introduce an adult rat (100-114 days of age) and a young rat (30-44 days of age) into an acrylic cage $(90 \mathrm{~cm} \times 90 \mathrm{~cm} \times 45 \mathrm{~cm})$, for two sessions separated by intervals of 30 (Experiment 1) or 15 (Experiment 2) minutes. Social contact was defined as exploration/sniffing the anogenital region of the rat. The difference in the time spent in social contact between the first and second sessions was defined as the memory index.

\section{Results}

No differences were observed in Experiment 1 due to the diet conditions. In Experiment 2, social contact decreased from the first to the second session in the controls $(p<0.05)$ in contrast to the malnourished animals, who showed no differences.

\section{Conclusion}

These results suggest that early protein malnutrition impairs the social memory in adult rats.

Indexing terms: protein malnutrition; social behavior; rats.

\section{N T R O D U Ç Ã O}

A desnutrição, especialmente a protéico-energética, tem sido um problema para grande parte da humanidade e freqüentemente aparece como causa de várias alterações no desenvolvimento humano. No entanto, os mecanismos que relacionam desnutrição e déficits de desenvolvimento ainda não estão totalmente estabelecidos' .

Em estudos experimentais com animais, algumas alterações produzidas pela desnutrição são mais evidentes, tais como a redução do peso corporal e determinadas alterações no desenvolvimento ${ }^{2,3}$. No entanto, há outras alterações estruturais e funcionais que são mais sutis e ocorrem em determinados períodos de desenvolvimento mais acelerado do cérebro, sendo, dependendo de sua natureza, passíveis de reversibilidade diante de reabilitação nutricional ${ }^{4,5}$.

Entre as alterações estruturais, as principais se referem ao menor número e tamanho de células cerebrais, assim como alterações na ramificação dendrítica e na camada de mielina dos neurônios ${ }^{4}$. Morgane et al. ${ }^{4}$ mostraram que várias regiões do cérebro também são bastante afetadas pela desnutrição precoce, como, por exemplo, o cerebelo e o sistema hipocampal. Quanto às alterações neuroquímicas, a desnutrição protéica altera o nível de neurotransmissores e o número e a afinidade de alguns receptores de vários sistemas de neurotransmissão, como o serotonérgico, o dopaminérgico, o gabaérgico e o colinérgico ${ }^{6}$. Além disso, algumas alterações neurofisiológicas produzidas pela desnutrição se referem essencialmente a prejuízos na plasticidade sináptica, como a alteração da habilidade de potencialização da neurotransmissão a longo prazo, modificações referentes ao limiar do kindling (abrasamento) e modificações no padrão do eletroencefalograma associadas ao comportamento do sono ${ }^{7}$. Finalmente, do ponto de vista funcional, a desnutrição influencia aspectos como a emoção, a motivação e a ansiedade, além de alterar processos envolvidos na memória e na aprendizagem ${ }^{5}$. Efeitos como a redução da ansiedade e/ou o aumento da impulsividade ${ }^{8,9} \mathrm{e}$ prejuízos em testes de aprendizagem ${ }^{10,11}$ são constantemente relatados. 
Entre as alterações comportamentais decorrentes da desnutrição protéica, o comportamento social tem recebido especial atenção, evidenciando que animais desnutridos no início da vida exploram menos e respondem menos à situação de contato social' ${ }^{12}$, sugerindo uma maior dependência e retardo neuromotor produzidos pela desnutrição precoce ${ }^{5}$.

Considerando as alterações no comportamento social citadas acima, e o fato de a desnutrição protéica no início da vida produzir alterações em mecanismos de aprendizagem e memória em diversos modelos experimentais ${ }^{13}$, este trabalho teve como objetivo investigar os efeitos desse tipo de desnutrição em um modelo experimental de memória social em ratos adultos. A memória social é formada durante o comportamento espontâneo de interação social e pode ser medida no animal com o auxílio de testes de reconhecimento social ${ }^{14}$ ou de discriminação social ${ }^{15}$.

\section{MÉ T O D O S}

Foram utilizados 18 ratos albinos ( 9 animais-controle e 9 desnutridos), machos, da linhagem Wistar (Rattus norvegicus), provenientes do Biotério Central do Campus de Ribeirão Preto da Universidade de São Paulo (USP). Esses 18 animais foram, aleatoriamente, escolhidos de um grupo de 36 ninhadas; da ninhada escolhida, no máximo dois animais machos compuseram os grupos testados. Os animais restantes foram utilizados em outros estudos do grupo de pesquisa. Ao final dos testes os animais foram sacrificados. Os experimentos foram conduzidos de acordo com recomendações da Sociedade Brasileira de Neurociências e Comportamento, baseadas no US National Institutes of Health Guide for Care and Use of Laboratory Animals.

Os filhotes e as ratas-mães foram recebidos no dia do nascimento (dia 0 ) e oito filhotes (seis machos e duas fêmeas) foram, aleatoriamente, designados para cada rata. Durante a lactação (0-21 dias) as ratas-mães foram alimentadas com dietas isocalóricas contendo 6\% (desnutridos) ou $16 \%$ (controle) de proteína ${ }^{16}$. A dieta-controle foi composta por $16 \%$ de proteína (caseína SKF, Alemanha), 60,8\% de amido de milho (Maizena ${ }^{\circledR}$ Refinarias de Milho Brasil), 5\% de salina (Rhoster, Brasil), 1\% de mistura de vitamina (Rhoster, Brasil), $8 \%$ de óleo de milho (Mazola ${ }^{\circledR}$ Refinarias de Milho Brasil) e 0,2\% de colina (Rhoster, Brasil). A dieta deficiente em proteína foi composta por $6,0 \%$ de proteína, $77,8 \%$ de amido de milho e a mesma porcentagem dos outros constituintes da dieta-controle. Ambas as dietas foram suplementadas com L-metionina (Dyets, USA) em 2,0 g/ $\mathrm{kg}$ de proteína, uma vez que a caseína é deficiente nesse aminoácido (Tabela 1).

As ninhadas foram mantidas até o final do período de lactação (21 dias) em caixas de polipropileno opacas $(30 \mathrm{~cm} \times 40 \mathrm{~cm} \times 20 \mathrm{~cm})$, forradas com raspas de madeira. Durante o período de lactação as ratas-mães e toda a ninhada foram pesadas semanalmente em balança eletrônica (Marte, Brasil). Após o desmame os animais viveram individualmente também em caixas medindo $30 \mathrm{~cm} \times 40 \mathrm{~cm} \times 20 \mathrm{~cm}$ até o final dos experimentos, sendo pesados semanalmente. Nessa fase, todos os animais tiveram livre acesso a uma ração comercial de laboratório (USP- Pirassununga, SP, Brasil), caracterizando assim o período de reabilitação nutricional para os animais desnutridos. Os animais

Tabela 1. Porcentagem dos componentes utilizados na preparação das dietas-controle e hipoprotéica.

\begin{tabular}{lrc}
\hline Componente & Controle & Hipoprotéica \\
\hline Proteína & 16,000 & 6,000 \\
L-Metionina & 0,032 & 0,012 \\
Carboidrato & 69,768 & 79,788 \\
Gordura & 8,000 & 8,000 \\
Mistura salina (AIN-93G) & 5,000 & 5,000 \\
Mistura vitamínica (AIN-93G) & 1,000 & 1,000 \\
Cloreto de colina & 0,200 & 0,200 \\
\hline Total & 100,000 & 100,000 \\
\hline
\end{tabular}

Fornecedores: proteína= caseína (SKF, Alemanha); L-metionina (Dyets, EUA); gordura= óleo de milho (Mazola ${ }^{\circledR}$ Refinarias de Milho Brasil); mistura salina (Rhoster Indústria e Comércio Ltda, Brasil); mistura vitamínica (Rhoster Indústria e Comércio Ltda, Brasil); cloreto de colina (Rhoster Indústria e Comércio Ltda, Brasil); carboidrato= amido de milho (Maizena ${ }^{\circledR}$ Refinarias de Milho Brasil). 
198 | V.C. SILVA \& S.S. ALMEIDA

que foram objetos de reconhecimento nos experimentos tinham de 30 a 45 dias de idade, provenientes do Biotério Central, e foram mantidos individualmente com livre acesso à água e à ração comercial (USP - Pirassununga, SP, Brasil) em caixas semelhantes aos animais tratados com dietas especiais. Os animais foram mantidos durante todo o experimento em um biotério com regime de temperatura controlada $\left(23 \pm 1^{\circ} \mathrm{C}\right)$ e ciclo de 12 horas de luz e 12 horas de escuro, com luz acesa a partir das 6 horas da manhã, e água à vontade.

Os experimentos foram realizados em uma arena quadrada com piso de madeira revestido de fórmica $(90 \mathrm{~cm} \times 90 \mathrm{~cm} \times 45 \mathrm{~cm})$ e paredes de acrílico transparente. A sala experimental foi iluminada por uma luz vermelha de $60 \mathrm{~W}$ colocada $80 \mathrm{~cm}$ acima do centro da arena. As sessões experimentais foram registradas por uma câmera de vídeo (Sony, Brasil) montada verticalmente sobre a arena. Para a análise das gravações foi utilizado um televisor em cores (Phillips, Brasil).

Os animais (110-114 dias de idade) foram familiarizados com a arena em sessões diárias de sete minutos por dois dias antes do início dos testes de memória social. O teste de memória social consistiu na colocação de um animal adulto e outro jovem (machos) na arena em duas sessões de exposição de sete minutos, separadas por um intervalo de tempo de 30 minutos (experimento 1) ou 15 minutos (experimento 2). Grupos independentes de animais foram utilizados em cada experimento. O animal jovem utilizado para reconhecimento era substituído entre sujeitos. Após a realização de cada sessão os animais foram mantidos individualmente em gaiolas na própria sala, para evitar o estresse causado pelo transporte, e a arena foi limpa com uma solução de álcool a $10 \%$, respeitando-se um intervalo mínimo de cinco minutos para que a arena secasse completamente. Em ambas as sessões, foi registrado o tempo de contato social, que consistia em todo contato feito pelo animal adulto em relação ao animal jovem, incluindo os comportamentos de se aproximar do animal jovem tocando-o com o focinho, podendo ainda cheirá-lo, limpá-lo (grooming) ou segui-lo ${ }^{14}$. Considerou-se como índice de memória social a diferença no tempo de contato social registrado entre a primeira e a segunda exposição. A análise das gravações das sessões foi realizada por dois observadores cegos para a condição nutricional dos animais, previamente treinados na observação dos comportamentos sociais a serem registrados e com índice de concordância entre observadores $\geq 80 \%$.

Os dados de peso corporal das ratas-mães e filhotes foram tratados por uma Análise de Variância (Anova - Programa Statistica versão 5.1) de dois fatores (dieta $x$ dia) com repetição no fator dia. Os dados comportamentais também foram tratados por uma Anova de dois fatores (dieta x sessões). Quando necessário, foi utilizado o teste de comparações múltiplas de Newman-Keuls com nível de significância de $p<0,05$.

\section{RESULTADOS E DISCUSSÃO}

A Anova mostrou um efeito significativo do fator dia sobre o peso corporal das ratas-mães $[F(3,30)=18,43 ; p<0,001]$ durante o período de lactação, mostrando uma perda de peso ao longo desse período. Entretanto, as ratas desnutridas perderam mais peso que as ratas-controle, levando a uma interação significativa dos fatores dieta e dia $[F(3,30)=13,46 ; p<0,001]$. Com relação ao peso dos filhotes durante a lactação (Figura 1) a Anova mostrou efeitos significativos dos fatores dieta $[F(1,10)=44,36 ; p<0,001]$, dia $[F(3,30)=166,35 ; p<0,001]$ e interação dieta $x$ dia $[F(3,30)=43,13 ; p<0,001]$. A análise post hoc revelou que nos dias 7, 14 e 21 da lactação os pesos dos filhotes desnutridos foram significativamente menores do que os pesos dos animais-controle $(p<0,05)$. Durante o período de recuperação nutricional dos animais (Figura 1), a Anova mostrou efeitos significativos dos fatores dieta $[F(1,16)=5,66 ; p<0,001]$, dia $[F(12,192)=503,12$; $p<0,001]$ e interação dieta e dia $[F(12,192)=2,46$; $p<0,001]$. A análise post hoc revelou que os animais desnutridos pesaram significativamente menos que os animais-controle em todas as idades, exceto aos 91, 105 e 112 dias. 


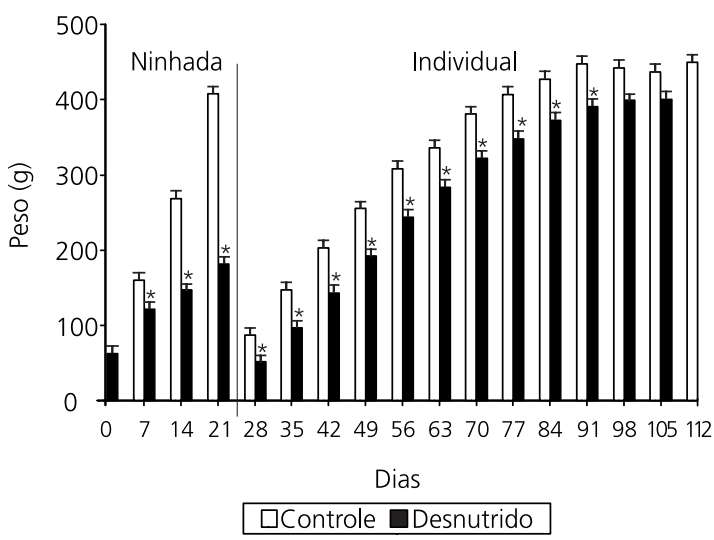

Figura 1. Peso corporal dos filhotes (média \pm erro-padrão da média-EPM) durante o período de lactação (0-21 dias de idade) e pós-lactação (28-112 dias de idade).

Nota: * $p<0,05$ em relação ao grupo-controle na mesma idade.

Esses dados mostram que a desnutrição protéica no início da vida produziu reduções de peso corporal tanto das ratas-mãe quanto dos filhotes. Tal redução já foi descrita em estudos, tanto do nosso laboratório ${ }^{3,17,18}$ quanto de outros ${ }^{2,19,20}$. A introdução de um longo período de recuperação nutricional não se mostrou suficiente para igualar os pesos dos animais desnutridos e dos animais-controle, o que revela que a desnutrição protéica no início da vida, mesmo que por um período curto (21 dias), é suficiente para produzir alterações permanentes no desenvolvimento dos animais. Deve-se ressaltar que uma vez que a dieta deficiente em proteína era introduzida no início da lactação, é possível que na primeira semana as ratas-mães tenham se utilizado de suas reservas corporais para nutrirem suas ninhadas. Nesse caso, o período de desnutrição pode ter sido ainda mais curto que os 21 dias do período de lactação. Entretanto, já aos 7 dias de idade observa-se peso significativamente menor dos animais desnutridos, quando comparados aos animais-controle.

Os dados do experimento 1 (Figura 2) indicam que não foram encontrados efeitos significativos de fatores como dieta, sessão, ou, ainda, de interação dieta $x$ sessão quando as sessões foram separadas por intervalos de 30 minutos. Nesse caso, tanto os animais desnutridos quanto os animais-controle não apresentaram redução do tempo despendido em contato social da primeira para a segunda sessão de exposição. Entretanto, os dados do experimento 2 (Figura 2) (intervalo de 15 minutos entre as sessões) mostraram uma redução significativa do tempo de contato apenas no grupo de animais-controle. Tal resultado produziu um efeito significativo da interação dos fatores dieta $\times$ sessão $[F(1,16)=4,83$; $p<0,05]$. Os animais desnutridos persistiram no contato e, por vezes, chegaram a aumentar o tempo de contato na segunda sessão de exposição ao animal jovem. A análise post hoc revelou, ainda, que a redução no tempo de contato social dos animais-controle da primeira para a segunda sessão foi estatisticamente significante $(p<0,05)$.

Os resultados obtidos com o grupo de animais-controle estão de acordo com outro estudo descrito na literatura ${ }^{14}$ e sugerem que esses animais retêm a informação adquirida na primeira sessão de exposição ao animal jovem. Entretanto, os animais desnutridos não apresentaram qualquer redução significativa no contato social entre sessões nos dois experimentos, indicando memória social prejudicada, pois não há retenção efetiva das informações da primeira sessão.

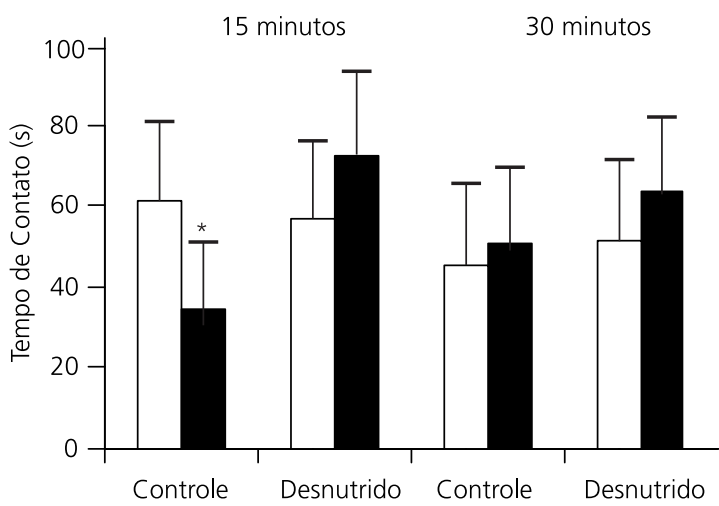

Sessão $1 \square$ Sessão 2

Figura 2. Tempo despendido pelos animais em contato social (média \pm EPM) nas duas sessões experimentais separadas por intervalos de 30 minutos (experimento 1) ou 15 minutos (experimento 2).

Nota $={ }^{*} p<0,05$ em relação à primeira sessão na mesma condição de dieta. 
Essa persistência na exploração do animal jovem por animais desnutridos no início da vida pode ser interpretada de várias maneiras. Em primeiro lugar, vários estudos dos efeitos da desnutrição protéica no início da vida sobre comportamento social dos animais ${ }^{12,18,21}$ revelaram alterações comportamentais já no início da vida desses animais, alterações que parecem determinantes para a compreensão do comportamento social dos animais adultos ${ }^{22}$. Entre as alterações comportamentais, uma maior responsividade e uma maior atividade social dos animais que sofreram desnutrição precoce foram relatadas por outros estudos ${ }^{23,24}$ e podem colaborar com a interpretação da persistência da exploração social observada neste estudo. Em segundo lugar, estudos de memória e aprendizagem descritos na literatura ${ }^{11,13}$ também indicam prejuízos no processo de retenção de informação e de aprendizagem por parte de animais desnutridos, assim como foi observado neste estudo. Além disso, a persistência na exploração de um estímulo já conhecido pode sugerir uma dificuldade de habituação desses animais à novidade. Tais dados estão de acordo com estudos que revelam os prejuízos de habituação nesses animais submetidos à desnutrição $0^{3,12}$.

Se considerarmos ainda que a diferença devida à dieta ocorreu apenas no experimento cujo intervalo entre as sessões era de apenas 15 minutos (experimento 2) e que dados semelhantes foram encontrados com intervalos que variavam de 15 minutos a uma hora ${ }^{25}$, o modelo usado neste estudo parece ser sensível apenas para intervalos pequenos de tempo entre as sessões. Dessa forma, a retenção das informações referentes à memória social parece ficar essencialmente prejudicada quando submetida a intervalos maiores, o que tem sido reforçado por outros estudos $^{14,26}$.

Algumas observações devem ser feitas também quanto às condições de realização deste estudo, uma vez que ele foi realizado durante a fase clara do ciclo claro/escuro, enquanto outros estudos sobre memória social foram realizados na fase escura, quando é maior a atividade dos ani- mais. Entretanto, estudos anteriores ${ }^{15}$ estão de acordo com este estudo, mostrando que o modelo é sensível para medir memória social mesmo quando os animais são testados na fase clara do ciclo de luz.

Finalmente, vale enfatizar que a desnutrição produz uma série de alterações no sistema de neurotransmissão gabaérgico, além de alterações estruturais no sistema hipocampal ${ }^{4}$, sistemas esses que parecem estar fundamentalmente envolvidos em mecanismos de memória social em ratos adultos ${ }^{27}$. Dessa forma, os dados encontrados nesta pesquisa devem servir de subsídio para outros estudos com o objetivo de investigar o significado funcional das alterações nesse sistema de neurotransmissão gabaérgico em tarefas de memória social em animais desnutridos. Tais estudos poderiam, ainda, incluir modelos que investiguem processos de discriminação social em animais que foram desnutridos no início da vida.

\section{O N CLUSÃ O}

Este estudo permite sugerir que a desnutrição protéica, no início da vida (durante o período de lactação) prejudica a memória social de ratos adultos, quando submetidos a sessões de reconhecimento separadas por intervalos de 15, mas não de 30 minutos. Esse prejuízo de memória social pode ser decorrente de alterações que a desnutrição no início da vida produz em estruturas cerebrais e sistemas de neurotransmissão, que podem estar envolvidos em processos de reconhecimento social em animais adultos.

\section{REFERÊ N CIAS}

1. Meeks Gardner, Grantham-McGregor SM, Chang SM, Himes JH, Powell CA. Activity and behavioral development in stunted and non-stunted children and response to nutritional supplementation. Child Dev. 1995; 66(6):1785-97.

2. Dobbing J. Early nutrition and later achievement. London: Academic Press; 1987.

3. Lima JG, Oliveira LM, Almeida SS. Effects of early concurrent protein malnutrition and environment stimulation on the central nervous system and behavior. Nutr Neurosci. 1999; 1:439-48. 
4. Morgane PJ, Austin K, Lafrance RJ, Bronzino JD, Tonkiss J, Diaz-Cintra S, et al. Prenatal malnutrition and development of the brain. Neurosci Biobehav Rev. 1993; 17(1):91-128.

5. Strupp BJ, Levitsky DA. Enduring cognitive effects of early malnutrition: a theoretical reappraisal. J Nutr. 1995; 125(8 Suppl):2221S-32S.

6. Almeida SS, Tonkiss J, Galler JR. Malnutrition and reactivity to drugs acting in the central nervous system. Neurosci Biobehav Rev. 1996; 20(3): 389-402.

7. Galler JR, Shumsky JS, Morgane PJ. Malnutrition and brain development. In: Walker WA, Watkins J, editors. Nutrition in Pediatrics. 2nd ed. Neuilly Sur-Seine, France: Plenum Press; 1996. p.194-210.

8. Almeida SS, Paiva RVS, Araújo M, Moreira GMS, Oliveira LM. Short-term social isolation does not reduce the elevated plus-maze exploration in early protein malnourished rats. Nutr Neurosci. 1998; 1:103-10.

9. Tonkiss J, Galler JR, Formica RN, Shukitt-Hale B, Timm RR. Fetal protein malnutrition impairs acquisition of a DRL task in adult rats. Physiol Behav. 1990; 48(1):73-7.

10. Córdoba NE, Arolfo MP, Brioni JD, Orsingher OA. Perinatal undernutrition impairs spatial learning in recovered adult rats. Acta Physiol Pharmacol Ther Latinoam. 1994; 44(3):70-6.

11. Castro CA, Tracy M, Rudy JW. Early-life undernutrition impairs the development of the learning and short-term memory processes mediating performance in a conditional-spatial discrimination task. Behav Brain Res. 1989; 32(3):255-64.

12. Almeida SS, Araujo M. Postnatal protein malnutrition affects play behavior and other social interactions in juvenile rats. Physiol Behav. 2001; 74(1-2):45-51.

13. Fukuda MT, Françolin-Silva AL, Almeida SS. Early postnatal protein malnutrition affects learning and memory in the distal but not in the proximal cue version of the Morris water maze. Behav Brain Res. 2002; 133(2):271-7.

14. Becker A Grecksch G. Social memory is impaired in neonatally ibotenic acid lesioned rats. Behav Brain Res. 2000; 109(1):137-40.

15. Reijmers LG, Leus IE, Burbach JP, Spruijt BM, van Ree JM. Social memory in the rat: circadian variation and effect of circadian rhythm disruption. Physiol Behav. 2001; 72(3):305-9.
16. Almeida SS, Garcia RA, Cibien MMR, De Araújo M, Moreira GMS, De Oliveira LM. The ontogeny of exploratory behaviors in early protein malnourished rats exposed to the elevated plus-maze test. Psychobiology. 1994; 22:283-8.

17. Araújo M, Almeida SS. Ontogeny of home-orienting behavior in rat pups during the first half of the lactation period: effects of early postnatal protein malnutrition on repeated but not single testing. Nutr Neurosci. 2000; 2:425-33.

18. Almeida SS, Tonkiss J, Galler JR. Prenatal protein malnutrition affects the social interactions of juvenile rats. Physiol Behav. 1996; 60(1): 197-201.

19. Bedi KS. Spatial learning ability of rats undernourished during early postnatal life. Physiol Behav. 1992; 51(5):1001-7.

20. Clarke KA, Parker AJ, Smart JL. Analysis of walking locomotion in adult female rats undernourished as sucklings. Physiol Behav. 1992; 52(4):823-6.

21. Loranca A, Torrero C, Salas M. Development of play behavior in neonatally undernourished rats. Physiol Behav. 1999; 66(1):3-10.

22. Meaney MJ, Stewart J. A descriptive study of social development in the rat (Rattus norvegicus). Anim Behav. 1981; 29:34-45.

23. Whatson TS, Smart JL, Dobbing J. Dominance relationships among previously undernourished and well fed male rats. Physiol Behav. 1975; 14(4):425-9.

24. Whatson TS, Smart JL Social behavior of rats following pre and early postnatal undernutrition. Physiol Behav. 1978; 20(6):749-53.

25. Thor DH, Holloway WR. Social memory of the male laboratory rat. J Comp Physiol Psychol. 1982; 96:1000-6.

26. Popik P, Wolterink G, De Brabander H, Van Ree JM. Neuropeptides related to [Arg8 ] vasopressin facilitates social recognition in rats. Physiol Behav. 1991; 49(6):1031-5.

27. Mondadori C, Moebius HJ, Zingg M. CGP 36,742, an orally active GABAB receptor antagonist, facilitates memory in a social recognition test in rats. Behav Brain Res. 1996; 77(1-2):227-9.

Recebido em: 15/3/2004

Versão final reapresentada em 5/1/2005 Aprovado em: 2/2/2005 